\title{
Evidências neuropsicológicas da existiência de um nódulo de aspecto
}

\author{
Neuropsychological evidences in favor of the existence \\ of an aspect node
}

\section{Celso Novaes \\ Universidade Federal do Rio de Janeiro - UFRJ}

\section{Abstract}

Assumindo que todas as línguas naturais compartilham das mesmas categorias funcionais, mostrando assim um alto grau de uniformidade, este trabalho apresenta algumas evidências neuropsicológicas que dizem respeito à dissociação entre a expressão lingüística de tempo e a expressão lingüística de aspecto, em indivíduos com patologia da linguagem - afasia de Broca. Essas evidências nos permitem defender a hipótese de que a camada flexional seria formada de pelo menos duas subcamadas, sendo uma dessas a camada que projeta independentemente os traços de aspecto. Essa hipótese vem ao encontro da proposta de Pollock (1989) de que a camada flexional seria constituída de dois nódulos e da proposta de Chomsky (1995) de que somente os traços semanticamente interpretáveis nas interfaces lingüísticas projetariam uma categoria funcional.

\section{Palavras-chave}

Categorias funcionais, Tempo e aspecto, Traços semanticamente interpretáveis, Dissociação de sintomas, Afasia de Broca.

\section{Abstract}

Assuming that natural languages share the same functional categories, showing a high degree of uniformity, this work presents some 
neuropsychological evidences concerning the dissociation between the linguistic expression of tense and the linguistic expression of aspect in individuals with problems of language - Broca's aphasia and specific linguistic impairment. These evidences allow us to defend the hypothesis that the inflectional layer would be constituted by two sublayers at least and one of these is the layer that projects independently the aspect features. This hypothesis is in line with Pollock's proposal that the inflectional layer would be constituted by two nodes and with Chomsky's proposal that only interpretable features at the linguistic interfaces project a functional category.

\section{Keywords}

Functional categories, Tense and aspect, Features conceptually motivated, Dissociations of symptoms, Broca's aphasia. 


\section{Introdução}

om o surgimento e o desenvolvimento da gramática gerativa a partir dos
anos 50 e a crença de que os princípios que regem a aquisição da
linguagem são específicos desse módulo, um dos grandes objetivos dos estudos da linguagem passou a ser a investigação de que como os diferentes constituintes da sentença estão representados nas nossas mentes.

Vários fenômenos sintáticos, universais ou específicos de determinadas línguas, têm sido investigados exaustivamente. Entre esses, podemos destacar o estudo da representação lingüística dos conceitos de concordância, tempo e aspecto. Tendo em vista que esses estudos focalizam a representação mental e não a representação física, sendo portanto de natureza abstrata, uma maneira de validá-los é exatamente através de estudos que investigam as alterações da linguagem em decorrência de lesões em áreas específicas do cérebro.

Nesse contexto, surgem nos anos 80 vários estudos preocupados em analisar as alterações lingüísticas decorrentes de lesões neurológicas utilizando o instrumental teórico oferecido pela gramática gerativa. Com esses estudos, passa a ser possível investigar, por exemplo, se uma determinada categoria funcional abriga um ou mais traços formais. A estratégia utilizada para se chegar a conclusões dessa naturezaé a observação da dissociação ou não de determinados comportamentos em situação de teste.

Neste trabalho, eu vou argumentar, a partir de dados neuropsicológicos oriundos de estudos com indivíduos afásicos de Broca, em favor da existência de pelo menos dois nódulos distintos na camada flexional da árvore sintática: um abrigando os traços de tempo e um outro abrigando os traços de aspecto.

Para tal, na primeira seção, eu vou fazer uma revisão de alguns estudos que vêm tentando caracterizar o modo como os diferentes elementos flexionais estão representados mentalmente. Na segunda seção, eu vou apresentar alguns dados de natureza neuropsicológica que evidenciam que os conceitos de tempo e aspecto são representados separadamente nas nossas mentes. Na terceira 
seção, eu vou discutir as implicações teóricas da dissociação entre tempo e aspecto, encontrada nos dados neuropsicológicos. Finalmente, na última seção, eu vou discutir alguns problemas residuais.

\section{Representação mental da flexão}

Os estudos da linguagem que tiveram início com o surgimento da gramática gerativa sempre adotaram a hipótese de que a mente seria formada por diferentes faculdades ou módulos, no espírito proposto em Fodor (1983). Em essência, dizer que a mente é formada por diferentes faculdades significa dizer que diferentes princípios mentais regem diferentes tipos de processos ou fenômenos. Assim, os princípios que regem a aquisição de linguagem seriam diferentes dos princípios que regem a aquisição de outros tipos de conhecimento.

Nos estudos lingüísticos na perspectiva gerativista, assume-se ainda que os princípios que regem a aquisição de sintaxe são diferentes dos princípios que regem a aquisição de fonologia, por exemplo. Mais contundentemente ainda, assume-se que os princípios lingüísticos que dão conta de um determinado tipo de conhecimento sintático são diferentes dos princípios que dão conta de outros tipos de conhecimento sintático.

Dentro desse espírito, um dos principais objetivos da gramática gerativa passou a ser explicar o conhecimento lingüístico que os indivíduos nativos têm da sua língua a partir da atuação de diferentes princípios lingüísticos. Paralelamente, a gramática gerativa tem procurado entender o que as línguas têm em comum e o que elas têm de diferente. Uma hipótese interessante sobre as variações entre as línguas, proposta por Chomsky (1993), estabelece que essas diferenças devem-se essencialmente a diferenças morfológicas. ${ }^{1}$ Dentro dessa perspectiva, vários estudos têm focalizado as categorias funcionais, categorias não lexicais que alojam, entre outros, traços flexionais.

Até quase o fim dos anos 80, acreditava-se que a árvore sintática possuísse uma camada flexional formada de uma única categoria funcional, que alojaria não somente os traços de tempo como também os traços de concordância. Pollock (1989), no entanto, mostra algumas evidências, a partir de um estudo comparativo entre o inglês e o francês, em favor da hipótese de que a camada flexional seria na verdade composta de dois nódulos sintagmáticos - um para tempo (TP) e outro para concordância (AGRP). Ele se baseou essencialmente nas diferentes 
posições ocupadas pelos verbos finito e não finito na língua francesa. Em sentenças finitas, o verbo no francês ocupa uma posição anterior ao marcador de negação pas, enquanto em sentenças não-finitas o verbo no francês ocupa uma posição posterior ao pas, conforme os exemplos abaixo:
a. Jean n'aime pas Marie.
b. Ne pas aimer Marie...5

A partir do contraste apresentado em (1), Pollock propõe que na árvore sintática que representa a sentença existiriam dois nódulos flexionais: um anterior ao marcador de negação (TP=IP) e outro posterior (AGRP). Assim, em (1a), o verbo (finito) ocuparia a posição de núcleo do sintagma de tempo, um sintagma, segundo Pollock, que dominaria o sintagma de concordância. Em (1b), o verbo (não finito) ocuparia exatamente a posição de núcleo do sintagma de concordância. O sintagma que projeta a negação ocuparia uma posição entre o sintagma de tempo e o sintagma de concordância, conforme a representação em (2) abaixo. Tanto o verbo finito quanto o não finito seriam gerados no sintagma verbal e se moveriam abstratamente para a camada flexional. ${ }^{2}$

(2)

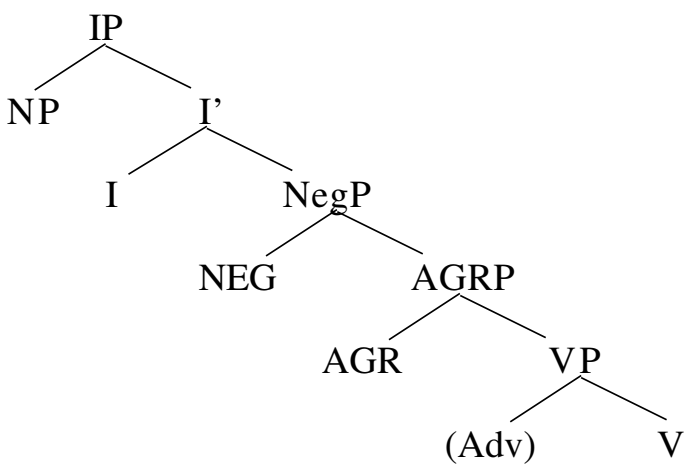

A idéia proposta por Pollock foi adotada e refinada por Chomsky (1991). Segundo esse autor, a representação linguiística da flexão seria um pouco mais sofisticada do que aquela proposta por Pollock. Para Chomsky, o nódulo de 6 concordância proposto por Pollock diria respeito somente à concordância de sujeito, sendo necessário portanto um nódulo de concordância para dar conta da concordância de objeto, morfologicamente realizada em algumas línguas, como por exemplo, o próprio francês, estudado por Pollock (1989). Assim, nesse momento 
da teoria, a camada flexional seria na verdade composta de três nódulos: dois para a concordância e um para tempo, conforme a representação em (3). ${ }^{3}$

(3)

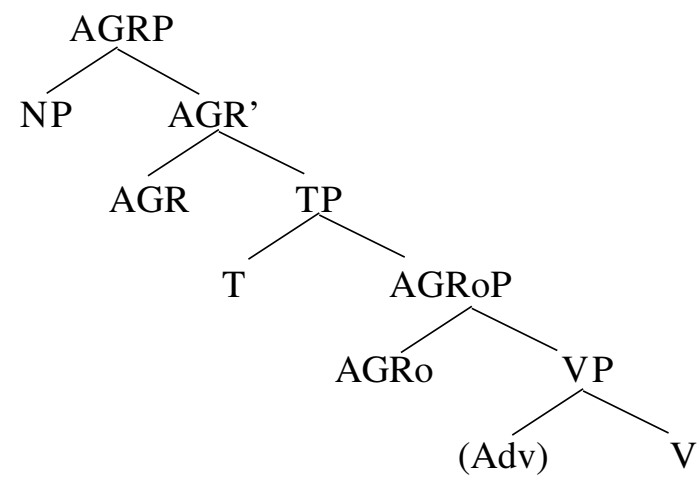

Com o advento do minimalismo e a proposta da existência de uma condição de legibilidade, segundo a qual as expressões lingüísticas produzidas pela faculdade de linguagem devem adequar-se às exigências dos sistemas de desempenho-sistema articulatório-perceptual e sistema conceptual-, Chomsky (1995) propõe que somente os traços conceptualmente motivados projetariam categorias funcionais. A consequiência imediata é a extinção de AGR como um nódulo funcional, tendo em vista que os traços de concordância, segundo Chomsky, não seriam semanticamente motivados. ${ }^{4.5}$ A eliminação de AGR como uma categoria funcional, no entanto, impõe uma reestruturação na árvore sintática no sentido de se definir que categoria funcional, alem de TP, abrigaria os elementos que se movem abstratamente. Independentemente de qual seja essa categoria, o certo é que a camada flexional deve ser formada, no mínimo, por duas categorias funcionais, sendo uma delas a camada que projeta os traços de tempo.

Os estudos resumidos acima argumentam em favor da idéia de que a camada flexional seja formada por pelo menos duas subcamadas, não sendo conclusivos no entanto em relação a que elementos constituiriam essas subcamadas e ao modo como se dariam as relações de dominância entre esses elementos.

Na próxima seção, eu vou tentar mostrar de que maneira os estudos com indivíduos com patologia da linguagem - afásicos de Broca-contribuíram para a sustentação da hipótese proposta por Pollock (1989) e refinada por Chomsky (1991, 1993, 1995) de que a camada flexional seria constituída por no mínimo dois nódulos sintáticos. 
Os argumentos explicitados na próxima seção levam em consideração a proposta de Cinque (1999) de que todos os traços conceptualmente interpretáveis devem ser núcleos de uma projeção máxima. Segundo essa proposta ainda, cada uma dessas projeções estaria especificada com um valor default e um valor marcado.

\section{Neuropsicologia e representação mental da flexão}

A partir dos anos 80, alguns trabalhos começam a ser desenvolvidos com o objetivo de estabelecer um diálogo entre as teorias propostas para dar conta do conhecimento linguístico dos indivíduos normais e as teorias propostas para dar conta do conhecimento lingüístico dos indivíduos com lesões em áreas cerebrais primariamente relacionadas com a linguagem (ver GRODZINSKY, 1984, 1990, entre outros).

Ao invés de se enfatizar simplesmente aquilo que é perdido ou preservado, os estudos em afasiologia lingüística passam a ver a linguagem do afásico como um sistema. A consequiência dessa postura é a necessidade de se analisar as diferenças do sistema linguístico do indivíduo afásico em relação ao sistema lingüístico do indivíduo não lesionado.

A busca para se entender o sistema linguístico do indivíduo afásico tomando como ponto de partida o instrumental teórico construído para os indivíduos normais deu origem a vários trabalhos. Um dos trabalhos nessa perspectiva é o de Grodzinsky (1990), que observa a dificuldade que os afásicos têm com sentenças passivas, interrogativas e relativas.

Essas sentenças, segundo Grodzinsky, teriam em comum o fato de serem geradas por movimento. Assim, a categoria abstrata movimento, proposta para dar conta de vários fenômenos observados em indivíduos normais, pôde ser validada a partir da análise das alterações lingüísticas observadas em certos grupos de afásicos, como por exemplo, os afásicos agramáticos com lesão na área de Broca, uma região situada no lobo frontal do hemisfério esquerdo.

Um outro tipo de contribuição para a constituição de um desenho da faculdade da linguagem vem de estudos envolvendo os morfemas flexionais, objeto de análise 9 deste trabalho. Desde a década de 70 que se observa que afásicos agramáticos têm problemas com a realização de morfemas flexionais. Este tipo de problema se mostrou tão recorrente que motivou a sua inserção na própria definição de agramatismo. No entanto, a partir dos anos 90, começou- 
se a observar que os afásicos não perdiam uniformemente todos os morfemas flexionais. A uniformidade da perda seria um indicador de que os traços correspondentes a esses morfemas flexionais estariam representados em um único nódulo funcional enquanto a não uniformidade da perda indicaria que traços flexionais diferentes estariam representados em nódulos diferentes.

Com o objetivo de contribuir para a construção de uma arquitetura da mente, a neuropsicologia vem adotando a estratégia metodológica da observação de dissociação de sintomas. Antes mesmo do trabalho de Pollock (1989), resumido na primeira seção, Jarema e Nespoulous (1984) já haviam demonstrado uma dissociação entre os morfemas de tempo e de número em afásicos nativos do francês, ou seja, os afásicos examinados apresentavam problemas com a realização morfológica de tempo mas não apresentavam qualquer problema com a realização morfológica de número e de gênero no sistema nominal, apontando assim para a possibilidade de que os traços correspondentes a tempo de um lado e de número e gênero de outro lado estivessem representados separadamente. O trabalho desenvolvido por esses autores, no entanto, não estava entre aqueles que tinham como objetivo explícito discutir a respeito do modo como a sintaxe está representada nas nossas mentes.

Um dos primeiros trabalhos a enfatizar a natureza sintática dos déficits apresentados por indivíduos afásicos com a morfologia flexional foi o de Hagiwara (1995). Segundo essa autora, as dificuldades dos afásicos nativos do japonês com a 10 morfologia de tempo e de negação seriam decorrentes da impossibilidade do verbo em acessar os nódulos mais altos da árvore sintática, ou seja, os nódulos acima do sintagma verbal.

Na mesma linha de pensamento de Hagiwara (1995), mas de uma maneira mais precisa, Friedmann e Grodzinsky (1997) propõem a hipótese da poda da árvore, segundo a qual a árvore sintática dos afásicos agramáticos seria podada em decorrência da lesão, tornando os pontos acima da poda inacessíveis ao verbo. Segundo esses autores, a poda se daria entre o sintagma de tempo e o sintagma de concordância, o que explicaria a dificuldade dos afásicos com a expressão lingüística de tempo mas não de concordância. ${ }^{6}$

De modo bastante interessante, essa hipótese vem ao encontro do proposto por Pollock (1989) para os indivíduos normais nas suas duas vertentes: primeiro, que tempo e concordância estariam representados em nódulos separados; segundo, que o nódulo de tempo dominaria o nódulo de concordância. 
A dissociação apontada por Friedmann e Grodzinsky (1997) pôde ser verificada em outras línguas. Dois afásicos nativos do português do Brasil relatados em Novaes (2004) também apresentaram problemas com a expressão lingüística de tempo mas não com a expressão lingüística de concordância. No entanto, ao invés de ver essa dissociação como o resultado da perda de nódulos em função de suas posições na árvore sintática, Novaes propõe que tal dissociação seja o resultado do fato de os traços de tempo mas não o de concordância serem semanticamente motivados, na linha proposta por Chomsky (1995). A hipótese de que a perda seja baseada na interpretabilidade semântica dos diferentes tipos de traços gramaticais nas interfaces lingüísticas - o sistema articulatórioperceptual e o sistema conceptualintencional - explicaria a preservação da expressão lingüística de concordância e a perda da expressão lingüística de tempo mas não resolveria o problema já anunciado na seção anterior sobre que categoria funcional, além de TP, constituiria a camada flexional.

A questão discutida no parágrafo anterior ganha novos elementos com a sofisticação da descrição e da análise de dados provenientes de indivíduos afásicos agramáticos. Um desses elementos vem do trabalho de Stavrakaki \& Kouvava (2003), que observaram uma dissociação entre a expressão lingüística de concordância, de tempo e de aspecto. A análise da fala espontânea dos dois pacientes examinados por essas autoras indicou uma alta taxa de acerto na expressão lingüística da concordância em oposição a uma baixa taxa de acerto na expressão lingüística de aspecto, sobretudo do aspecto perfectivo quando combinado com o tempo passado. A dissociação encontrada pelas autoras foi interpretada não como uma evidência da dificuldade de pacientes agramáticos em projetarem a árvore sintática, na linha proposta por Friedmann e Grodzinsky (1997), mas sim como uma dificuldade do verbo em acessar os nódulos mais altos dessa árvore. Assim, a dificuldade com a expressão lingüística de aspecto foi interpretada pelas autoras como uma dificuldade do verbo em acessar o nódulo aspectual.

Uma outra contribuição vem do trabalho de Novaes \& Braga (2005), que reinterpretaram a dificuldade de indivíduos afásicos agramáticos com a expressão lingüística de tempo como um problema decorrente da dificuldade de expressar lingüisticamente o conceito de aspecto. Os autores registraram dados de fala espontânea e submeteram um paciente a um teste de anagrama. Em ambas as situações, o paciente demonstrou mais dificuldade com a produção de imperfectivo do que com perfectivo, conforme demonstra o fragmento de fala espontânea em (4). 
Entrevistador: Como foi o seu final de semana?

Paciente: É...sábado...é...não quis minha casa sábado. Aí depois... à noite... choveu. Tomei banho, depois eu fui ver a cozinha. A laje.... molhado, molhado!

Nas situações em que o paciente deveria produzir o verbo no pretérito perfeito, ele o fez aparentemente sem problema. Por outro lado, nas situações em que deveria produzir o pretérito imperfeito, o paciente não o fez, o que indica certa dificuldade na produção de enunciados com verbos nesse tempo verbal. Nessas situações, o paciente prefere omitir o verbo, como no exemplo acima, onde ele poderia ter usado a forma "estava" na sentença em que ele descreve que a laje estava molhada. ${ }^{7}$

Considerando que o paciente demonstrou ter conservado o conceito de tempo e, em particular, o conceito de passado, o problema com a expressão lingüística do imperfectivo foi interpretado como uma decorrência da dificuldade do paciente em acessar às informações de aspecto na árvore sintática. O bom desempenho do indivíduo testado com a expressão lingüística do perfectivo foi interpretado pelos autores como decorrente do fato de o perfectivo ser o traço default. Dessa maneira, Novaes e Braga propõem uma nova hipótese: a de que os traços de aspecto projetariam uma categoria funcional que, junto com TP, constituiria a camada flexional. Segundo esses autores ainda, o fato de o paciente ter problema com a expressão lingüística de aspecto mas não com a expressão lingüística de tempo seria uma evidência em favor da hipótese de que o nódulo aspectual estaria situado acima do nódulo de tempo. Este tipo de raciocínio está de acordo com o espírito da hipótese da poda da árvore, proposto por Friedmann e Grodzinsky (1997).

Uma outra evidência de natureza neuropsicológica sobre a existência de um nódulo aspectual vem do trabalho de Maia (2006), no qual ela testou a compreensão de quatro pacientes afásicos num teste de relacionamento figurasentença. Esses pacientes tiveram dificuldade com a compreensão do perfectivo mas não com a compreensão do imperfectivo. Assim, enquanto o paciente examinado por Novaes \& Braga (2005) apresentou dificuldade com o imperfectivo, o paciente analisado por Maia (2006) apresentou dificuldade com o perfectivo8. Esses resultados evidenciam que, além de terem independência mental, os traços aspectuais de perfectivo e imperfectivo estão dissociados dos traços de tempo. Utilizando o mesmo modo de pensar expresso em Novaes \& Braga (2005), Maia propõe a existência de um nódulo aspectual dominando o nódulo de tempo. 
As evidências de natureza neuropsicológica em favor da existência de um nódulo aspectual mostradas aqui vêm corroborar algumas propostas a respeito da existência desse nódulo, feitas a partir de dados oriundos de indivíduos não lesionados (ver, entre outros, KOOPMAN; SPORTICHE, 1991 e BOK-BENNEMA, 2001).

Na próxima seção, eu vou tratar das implicações teóricas dessa dissociação entre tempo e aspecto.

\section{Implicações teóricas da dissociação entre a expressão lingǘstica de tempo e de aspecto}

A discussão sobre o modo como os diferentes traços formais estão representados mentalmente não é nova. Desde que se propôs a existência de uma camada flexional, no início dos anos 80, que se discute a respeito da distribuição dos diferentes tipos de traços flexionais nessa camada. Em Chomsky (1981), foi proposto que uma única categoria sintagmática abrigaria ao mesmo tempo os traços referentes a tempo e a concordância.

Desde 1989, no entanto, dois fatos têm impulsionado uma mudança na estrutura da árvore sintática, sobretudo no que diz respeito à camada flexional: primeiro, a proposta de Pollock (1989) de cisão da camada flexional, que passaria a ser constituída por um sintagma contendo informações referente a tempo, situado acima do marcador de negação, e um sintagma contendo informações referentes à concordância, situado abaixo do marcador de negação; segundo, a proposta de Chomsky (1995) de que os traços de concordância não projetariam uma categoria funcional.

Se a camada flexional é composta por dois nódulos, além do nódulo de negação, como propõe Pollock, e a concordância não projeta um sintagma, como propõe Chomsky, então algum outro tipo de traço tem que projetar um sintagma para, junto com o sintagma de tempo, formar a camada flexional. Várias propostas têm surgido com o objetivo de solucionar esse problema. A proposta de Chomsky (1995) é de que a camada flexional seria formada por um sintagma vP, projeção de um verbo leve que introduz sintagmas verbais, que, junto com TP, assumiria o papel de receber os elementos movidos em direção a essa camada. A universalidade de vP, no entanto, não é clara. É possível que a sua presença seja restrita a orações contendo múltiplos argumentos. ${ }^{9}$ Além disso, o verbo leve v, segundo Kitahara (1997), não tem interpretabilidade semântica, tendo sua presença justificada apenas por razões internas à teoria. ${ }^{10}$ 
Alguns dados de natureza neuropsicológica apresentados na seção anterior têm deixado em aberto a possibilidade de os traços de aspecto projetarem independentemente um sintagma. Os pacientes descritos nos trabalhos relatados acima tiveram afetada a expressão lingüística de aspecto sem ter afetada a expressão lingüística de tempo, sugerindo assim a possibilidade da existência de um sintagma que seria a projeção do traço de aspecto. Nesse caso, o sintagma de aspecto comporia a camada flexional junto com o sintagma de tempo.

Levando em consideração a proposta de Chomsky (1995) de que somente os traços semanticamente interpretáveis nas interfaces do sistema lingüístico projetariam um sintagma, o fato de os traços de aspecto serem semanticamente interpretáveis torna a hipótese da existência de um sintagma que seja o resultado de sua projeção bastante plausível.

Os dados de natureza neuropsicológica, além de sugerirem a existência de um nódulo aspectual, sugerem também a possibilidade da existência de um terceiro nódulo na camada flexional. O paciente descrito por Novaes \& Braga (2005), por exemplo, tende a produzir a forma não finita do verbo toda vez que apresenta problema com a expressão lingüística do imperfectivo. Esse fato foi interpretado como o resultado da existência de um nódulo contendo informações a respeito da finitude, que dominaria imediatamente o sintagma verbal. Aidéia é que o verbo checaria obrigatoriamente a sua finitude e, uma vez finito, checaria os traços de tempo e, em seguida, os traços de aspecto.

Diante dos fatos expostos acima, a camada flexional da árvore sintática seria constituída minimamente de três nódulos: um com o objetivo de checar os traços de finitude, um segundo com o objetivo de checar os traços de tempo e, finalmente, um terceiro com o objetivo de checar os traços de aspecto, conforme a representação em (5).

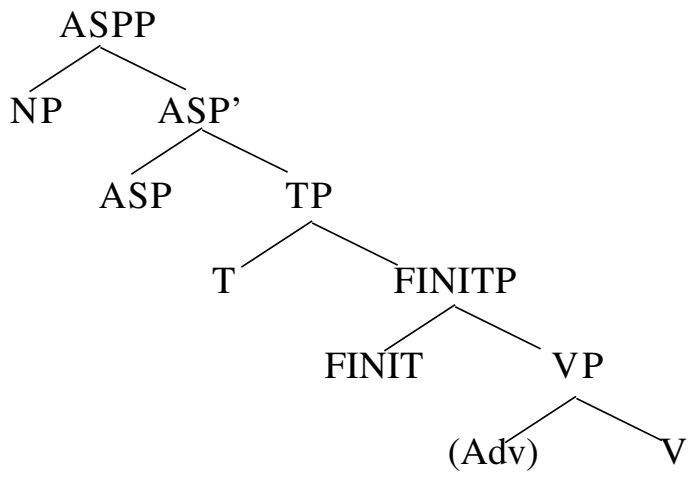


Nesse sistema, o verbo minimamente se moveria para checar os traços de finitude. Uma vez finito, ele se moveria para checar os traços de tempo e, uma vez checado esse tipo de traço, ele subiria para checar os traços de aspecto. A camada de finitude seria aquela que abrigaria o verbo não finito no francês, em consonância com a proposta de Pollock (1989). ${ }^{11}$

A hipótese de que a camada flexional seja formada por três nódulos sintagmáticos, abrigando os traços de finitude, tempo e aspecto separadamente coloca em xeque a hipótese aventada por Novaes (2004) de que o problema com a expressão lingüística de aspecto estaria relacionado ao fato de os traços de aspecto serem semanticamente motivados, uma vez que esses três tipos diferentes de traços são todos semanticamente interpretáveis nas interfaces lingüísticas. Uma hipótese alternativa é que o problema com a expressão lingüística de aspecto seja decorrente exclusivamente da posição que o sintagma ocupa na árvore sintática, no espírito proposto pela hipótese da poda da árvore (FRIEDMANN; GRODZINSKY, 1997).

As propostas desenvolvidas nesta seção incorporam a hipótese de que a árvore sintática que representa mentalmente a sentença consiste de três camadas diferentes: uma camada lexical, uma camada flexional e uma camada periférica (RIZZI, 1997).

\section{Considerações finais}

Este trabalho teve como objetivo argumentar, a partir de dados neuropsicológicos, em favor de uma reestruturação da camada flexional da árvore sintática. Além de um sintagma de tempo, os dados considerados na seção anterior parecem evidenciar a existência de um sintagma de aspecto e de um sintagma de finitude.

A reestruturação descrita no parágrafo anterior se baseia na tendência dos estudos neuropsicológicos e, em especial, da neurolingüística, de levar em consideração a observação da dissociação de processos ou sintomas. A análise de possíveis dissociações, como as descritas neste trabalho, vem-se constituindo numa importante ferramenta no sentido de mostrar que princípios estão atuando na manifestação de determinados fenômenos lingüísticos.

O status da dissociação nos estudos neuropsicológicos, no entanto, não é totalmente claro. Há autores, como Dunn (2003), que entendem que é impossível evidenciar que os dados caracterizem inequivocamente uma dissociação, desde 
que, segundo ele, a tarefa impedida pode simplesmente ser menos sensível à manipulação.Assim, Dunn rejeita a inferência da existência de dissociação quando essa é baseada em uma única tarefa. Além disso, o autor acrescenta que a inferência da existência de dissociações deveria somente ser feita a partir de casos de lesões puras, ou seja, lesões que afetam um módulo mas não outro. Todos esses argumentos poriam em xeque o uso da dissociação como um modo de demonstrar que determinadas funções mentais são separadas.

Chamando a atenção para o fato que não se pode utilizar os dados para inferir uma teoria, Coltheart \& Davies (2003) contestam os argumentos apresentados por Dunn e sustentam a tese de que a dissociação evidenciada em alguns dados de natureza neuropsicológica podem ser úteis para confirmar as previsões feitas a partir de algum quadro teórico, iluminando assim a descoberta dos princípios que estão atuando na determinação de diferentes fenômenos mentais. É a esta última perspectiva que este trabalho se filia.

Independentemente da validade da utilização da dissociação como uma estratégia para a elucidação dos princípios que subjazem aos diferentes fenômenos mentais, não há dúvida de que muito se pode aprender sobre o modo como o conhecimento lingüístico está representado nas nossas mentes olhandose para as mentes de indivíduos com lesões em áreas do cérebro que resultem em algum tipo de déficit lingüístico.

Dados oriundos de testes aplicados a indivíduos afásicos de Broca, discutidos neste trabalho, têm mostrado que esses pacientes podem apresentar problemas com a expressão lingüística de aspecto sem apresentar problemas com a expressão lingüística de tempo. Esses estudos vêm ao encontro de propostas feitas a partir de dados de indivíduos não lesionados, que defendem que os traços de aspecto projetem um nódulo na árvore sintática (ver, entre outros, KOOPMAN \& SPORTICHE, 1991 e BOK-BENNEMA, 2001).

A proposta de que aspecto constitua um nódulo na árvore sintática vem também ao encontro da hipótese de que os sintagmas que abrigam informações de natureza funcional são projeções de traços que sejam semanticamente interpretáveis (CHOMSKY, 1995). Sendo aspecto um traço semanticamente interpretável, é de se esperar que ele possa projetar um nódulo. Uma alternativa à proposta acima seria que o traço de aspecto, ainda que semanticamente interpretável, constituísse um único nódulo junto com o traço de tempo, hipótese que parece refutada pelos dados apresentados neste trabalho. 
Uma questão residual interessante diz respeito ao fato de a proposta de existência de um nódulo de aspecto poder aplicar-se a todas as línguas naturais, independentemente do modo como as informações relativas a aspecto sejam morfologicamente realizadas. Uma maneira de estender essa proposta a todas as línguasé incorporar a hipótese de que as línguas e as suas configurações sintáticas são uniformes, na linha proposta por Cinque (2006) e, mais contundentemente, por Sigurðsson (2005). ${ }^{12}$ Nesse sentido, as línguas se diferenciariam somente no modo como as informações relativas a aspecto são morfologicamente realizadas pelo sistema lingüístico e não no modo como as essas informações estariam representadas na sintaxe estrita.

\section{Notas}

${ }^{1}$ A hipótese de que as variações entre línguas devem-se essencialmente a diferenças morfológicas tem consequiência também sobre a estrutura da frase. Ou seja, ao adotar essa hipótese, estou assumindo a impossibilidade de variação na estrutura da árvore sintática, assunto de diversos debates (ver, entre outros, TRAVIS, 1991).

${ }^{2}$ No caso dos verbos do francês, e ao contrário dos verbos do inglês, esse movimento se daria na sintaxe aberta, ou seja, antes de spell-out, o momento a partir do qual o sistema computacional não pode mais ter acesso ao léxico.

${ }^{3}$ Não está representado aqui o sintagma de negação.

${ }^{4}$ A proposta de Chomsky (1995) de que os traços de concordância não seriam interpretáveis pelos sistemas de desempeno está longe de ser consensual. Segundo van Valin (2003), por exemplo, em lakhota os traços de concordância seriam interpretáveis.

${ }^{5}$ A concordância entre o sujeito e o verbo passa a ser vista na teoria como uma relação de associaçãoentre diferentes posições na árvore sintática, qual seja uma relação entre o núcleo e o especificador de um mesmo sintagma.

${ }^{6}$ Segundo esses autores ainda, dependendo da extensão da lesão, o ponto da poda pode variar, podendo também ocorrer entre o sintagma verbal e o sintagma de concordância ou entre o sintagma de tempo e o sintagma complementizador.

${ }^{7}$ Friedmann (2000) apresenta dados que evidenciam que, diante da dificuldade de produzirem certas formas, pacientes agramáticos produzem formas específicas em cada língua (gerúndios no inglês e particípios no italiano, por exemplo). No português, nossos dados parecem demonstrar que essa forma seria o infinitivo. 
${ }^{8} \mathrm{O}$ fato de o paciente analisado por Maia (2006) ter apresentado problema com o perfectivo mas não o com o imperfectivo, o oposto portanto do verificado por Novaes \& Braga (2005), põe em xeque a hipótese de que o perfectivo seja o traço default. É possível, no entanto, que os pacientes examinados por Maia tenham tinham um desempenho melhor com as sentenças que diziam respeito ao imperfectivo porque essas eram apresentadas na forma auxiliar mais gerúndio e não no imperfeito como em Novaes \& Braga.

${ }^{9}$ Chomsky estende a proposta da existência de verbos leves a orações transitivas (CHOMSKY, 1995, cap.4).

${ }^{10}$ Arad (2002) propõe que v pode abrigar diferentes tipos de traços, sendo a transitividades apenas um desses traços.

${ }^{11}$ Neste sistema, seria possível pensar que os traços de concordância estariam alojados no sintagma de finitude, o que explicaria a existência no português das orações flexionadas para concordância mas não para tempo.

${ }^{12}$ Sigurðsson argumenta em favor da idéia de que as línguas são uniformes, em oposição à idéia de que as línguas fazem uma seleção de traços a partir de um conjunto de traços universais. Segundo essa proposta, todas as línguas têm o mesmo conjunto de traços na sintaxe estrita.

\section{Referências Bibliográficas}

ARAD, M. Universal features and language-particular morphemes. In: ALEXIADOU, Artemis. Theoretical Approaches to Universals. Amsterdam: John Benjamins, 2002.

BOK-BENEMA, R. Evidence for an aspectual functional head in French and Spanish. In: OOSTERDORP, Mark van; ANAGNOSTOPOULOU, Elena. Progress in Grammar. Articles on the 20th anniversary of the comparison of grammatical models Group in Tilburg. www.meertens.nl/books/progressingrammar, 2001.

CHOMSKY, N. Some notes on economy of derivation and representation. In: FREIDIN, R. (Ed.). Principles and parameters in comparative grammar. Cambridge (MA): MIT Press, 1991.

CHOMSKY, N. A minimalist program for linguistic theory. In: HALE, K.; KEYSER, S.J. (Eds.). The view from building 20. Cambridge (MA): MIT Press, 1993.

CHOMSKY, N. The minimalist program. Cambridge (MA): MIT Press, 1995.

CINQUE, G. Adverbs and functional heads: a cross-linguistics perspective. New York: Oxford University Press, 1999. 
CINQUE, G. Restructuring and functional heads. New York: Oxford University Press, 2006.

COLTHEART, M.; DAVIES, M. Inference and explanation in cognitive neuropsychology. Cortex, v. 39, p. 188-191, 2003.

DUNN, J. The elusive dissociation. Cortex, v. 39, p. 177-179, 2003.

FODOR, J. The Modularity of Mind. Cambridge (MA): MIT Press, 1983.

FRIEDMANN, N. Moving verbs in agrammatic production. In: BASTIAANSE, R.; GRODZINSKY, Y. (Eds.). Grammatical disorders in aphasia: A neurolinguistic perspective. London: Whurr, 2000.

FRIEDMANN, N.; GRODZINSKY, Y. Tense and agreement in agrammatic production: pruning the syntactic tree. Brain and Language, v. 56, p. 397-425, 1997.

GRODZINSKY, Y. The syntactic characterization of agrammatism. Cognition, v. 16, p. 99-120, 1984.

GRODZINSKY, Y. Theoretical perspectives on language deficits. Cambridge (MA): MIT Press, 1990.

HAGIWARA, H. The breakdown of functional categories and the economy of derivation. Brain and Language, v. 50, p. 92-116, 1995.

JAREMA, G.; NESPOULUS, J.-L. Infinitif et flexions verbales chez l'aphasique agrammatique. La Linguistique, v. 20, p. 90-113, 1984.

KITAHARA, H. Elementary operations and optimal derivations. Cambridge (MA): MIT Press, 1997.

KOOPMAN, H.; SPORTICHE, D. The position of subjects. Lingua, v. 85, p. 211259, 1991.

MAIA, N. Uma visão metodológica dos estudos de caso em contraponto aos estudos de grupo em neurolingüística. 2006. Dissertação (Mestrado) - Universidade Federal do Rio de Janeiro.

NOVAES, C. Minimalism, nature of features and neuropsychological syndromes affecting language. Paper presented at The Annual Meeting of Theoretical and Experimental Neuropsychology. Montreal, Canada, 2004.

NOVAES, C.; BRAGA, M. Agrammatic aphasia and aspect. Brain and Language, v. 95, p. 121-122, 2005.

POLLOCK, J-Y. Verb movement, universal grammar and the structure of IP. Linguistic Inquiry, v. 20, p. 365-424, 1989. 
RIZZI, L. The fine structure of the left periphery. In: HAEGEMAN, Liliane. Elements of Grammar. Dordrecht: Kluwer Academic Publishers, 1997.

SIGURðSSON, H. Meaningful silence, meaningless sounds. In: PICA, Pierre. Linguistic variation yearbook. Amsterdam: John Benjamins, 2005.

STAVRAKAKI, S.; KOUVAVA, S. Functional categories in agrammatism: evidence from Greek. Brain and Language, v. 86, p. 129-141, 2003.

TRAVIS, L. Parameters of phrase structure and verb-second phenomena. In: FREIDIN, Robert (Ed.). Principles and parameters in comparative grammar. Cambridge (MA): MIT Press, 1991.

Van VALIN, R. Linguistic diversity and theoretical assumptions. (ms), 2003. 